\title{
An Inclusive Musical Mechatronics Course
}

\author{
https://doi.org/10.3991/ijep.v7i1.6641 \\ Dale A. Carnegie \\ Victoria University of Wellington, Wellington, New Zealand \\ dale.carnegie@vuw.ac.nz \\ Mo H. Zareei \\ Victoria University of Wellington, Wellington, New Zealand \\ mo. zareei@vuw.ac.nz \\ Jim Murphy \\ Victoria University of Wellington, Wellington, New Zealand \\ jim.murphy@vuw.ac.nz \\ Craig Watterson \\ Victoria University of Wellington, Wellington, New Zealand \\ craig.wattersonevuw.ac.nz
}

\begin{abstract}
This paper presents the design of a novel course in mechatronics, based on a project-based learning pedagogical philosophy that uses music as the theme to introduce to a diverse range of learners, the essential concepts of mechatronic practice. The course is designed at a post-graduate level and is targeted at international students who are likely to have a diverse range of background knowledge and potentially even a greater diversity in practical experience. The course builds upon our knowledge and capability in the construction or instrumentation of musical devices and cumulates in the design of a new mechatronic chordophone and the preparation of an IEEE conference paper submission.
\end{abstract}

Key Words - musical mechatronics, project based learning, diverse learners.

\section{$1 \quad$ Introduction}

An opportunity and a challenge has recently presented itself. Our university was successful in a collaborative bid for one of New Zealand's three recently Government funded ICT Graduate Schools. This bid was competitive with strong submissions from all of New Zealand's leading ICT tertiary providers. The purpose of these Graduate Schools is to increase the number of ICT skilled students entering the New Zealand workforce given that local industries are unable to fill their current ICT vacancies. The NZ Government is prepared to fund the establishment and initial running costs of such a centre up to approximately $\$ 10 \mathrm{~m}$ (USD). Our bid was chosen over our competitors on the basis of the innovative degree programmes we proposed. 
This paper details the construction of a novel mechatronics course that will be accommodated both within our new Master of Engineering Practice (MEP) degree designed for international students wishing to enter our ICT Graduate School, and also within our Bachelor of Engineering (Hons) (BE[Hons]) degree that is dominated by domestic students. There are multiple challenges in designing such a course:

- It must accommodate students with a wide variety of prior technical experience

- It must accommodate students with a variety of different learning styles

- It must provide advanced level instruction and development of mechatronic skills

- It should enthuse and motivate students, and ideally become a flagship course to promote both the MEP and BE(Hons) degrees.

To achieve these goals, we decided to base the course around a practical project, embracing a Project Based Learning (PBL) pedagogy. This paper was originally written when the course was being planned and as students were first enrolling. Of course what is planned, and what eventuates, can be different. Section IX of this paper details the actual results of the running of this paper. Although the course was very successful, not all of our intentions were realized.

\section{Background Context}

Taught master's courses proliferate internationally, with a huge number of universities offering some form of them. However, very often such programmes only emphasise the acquisition of technical knowledge, which can have little industry relevance, and can do little to develop independent or group project skills. The NZ Government was very clear in its aspirations for the ICT Graduate School in that it had to be industry focused, with the goal of addressing the ICT skills deficit faced by NZ employers. Our Faculty approached this problem from both a domestic and an international student framework. For international students we created the Master of Engineering Practice (MEP) degree.

The MEP is a 180 point programme, delivered over three trimesters or 12 months. It starts in November to better align with Northern Hemisphere student demand (in New Zealand, the domestic teaching year starts in March). Unlike traditional taught master's programmes, ours specifically develops the skills required by employers:

- High quality English technical communication skills (written and oral)

- Ability to work independently

- Ability to work in group environments

- High level technical capability.

- Relevant work experience.

The first trimester of the programme comprises two technical courses: a course on Research and Communication and a course on Individual Engineering Practice to develop individual research and project skills. Trimester 2 comprises another two technical courses and a Group Engineering Project. Trimester 3 is a paid internship in a NZ company where a complex problem is undertaken under both industry and aca- 
demic supervision. The MEP is currently offered in two streams, mechatronics and software engineering. Cyber-security and sustainable energy streams will be introduced in the near future. Further details of this course can be found in [1]. The Musical Mechatronics Course, ECEN427, is created as a core course in the MEP, but will also be offered to our final year BE (Hons) students (in a different trimester). Note that the final year courses of a BE (hons) degree are at a master's level, hence facilitating this dual offering.

\section{$3 \quad$ Why Project Based Learning?}

It has been widely publicised that traditional methods of tertiary education in engineering are failing to deliver enough engineering graduates. Mills and Treagast [2] summarised the critical issues facing traditional engineering education in the following six points:

- Engineering curricula are too focused on engineering science and technical courses without providing sufficient integration of these topics or relating them to industrial practice. Programs are content driven.

- Current programs do not provide sufficient design experiences to students.

- Graduates still lack communication skills and teamwork experience and programs need to incorporate more opportunities for students to develop these.

- Programs need to develop more awareness amongst students of the social, environmental, economic and legal issues that are part of the reality of modern engineering practice.

- Existing faculty lack practical experience, hence are not able to adequately relate theory to practice or provide design experiences. Present promotion systems reward research activities and not practical experience or teaching expertise.

- The existing teaching and learning strategies or culture in engineering programs is outdated and needs to become more student-centred.

Project based learning is an alternative which has received some success in engineering education through its use of active learning and student centred pedagogical approach [3-4].

PBL acts to enhance student participation in the learning process and increases the students' ability to communicate and develop critical thinking. Importantly, it also provides a learning environment that is applicable to a wide range of student learning styles, making it an ideal mechanism for teaching groups of diverse students, such as international students, students from different cultural backgrounds, and students with differing academic levels. PBL has also shown itself to be extremely good at increasing the participation of female students [5-9]. 


\section{$4 \quad$ Music Inspiration}

The authors of this paper recently reported on the success of a sophomore engineering course that uses music and sound to stimulate a basic understanding of sensors, actuators, data acquisition, microcontrollers and CAD/CAM techniques. The course was highly successful in motivating and engaging students, and the emphasis on creativity and innovation yielded projects well beyond the expectations of the faculty [10].

Such a use of musical and aural platforms to inspire and provide context to learning is not in itself new. For example, Misra, Blank, and Kumar use a musical paradigm focused on sound synthesis techniques and computer-generated music in teaching introductory computing [11]. Further examples can be found in [12-14].

Our university is extremely well placed to engage with a musical motivation. In collaboration with the New Zealand School of Music and the California Institute of the Arts (regularly ranked as one of the top fine arts Colleges in the USA), we have established a world-ranked research centre in the field of the intersection of sonic arts and engineering. Successful previous projects include the mechanical bass guitar, MechBass [15] (Fig. 1), that now has over 700,000 YouTube hits (for example [16]), the modular 6 string guitar Swivel 2 (Fig. 2) [17], the integrated mechatronic guitar StrumBot [18] (Fig. 3), and a number of other mechatronic instruments detailed in [19-20]. This provides us with the expertise to successfully utilise PBL in the development and delivery of a mechatronic music course as well as the ability to motivate the students by an inspirational demonstration of some of these developed devices.

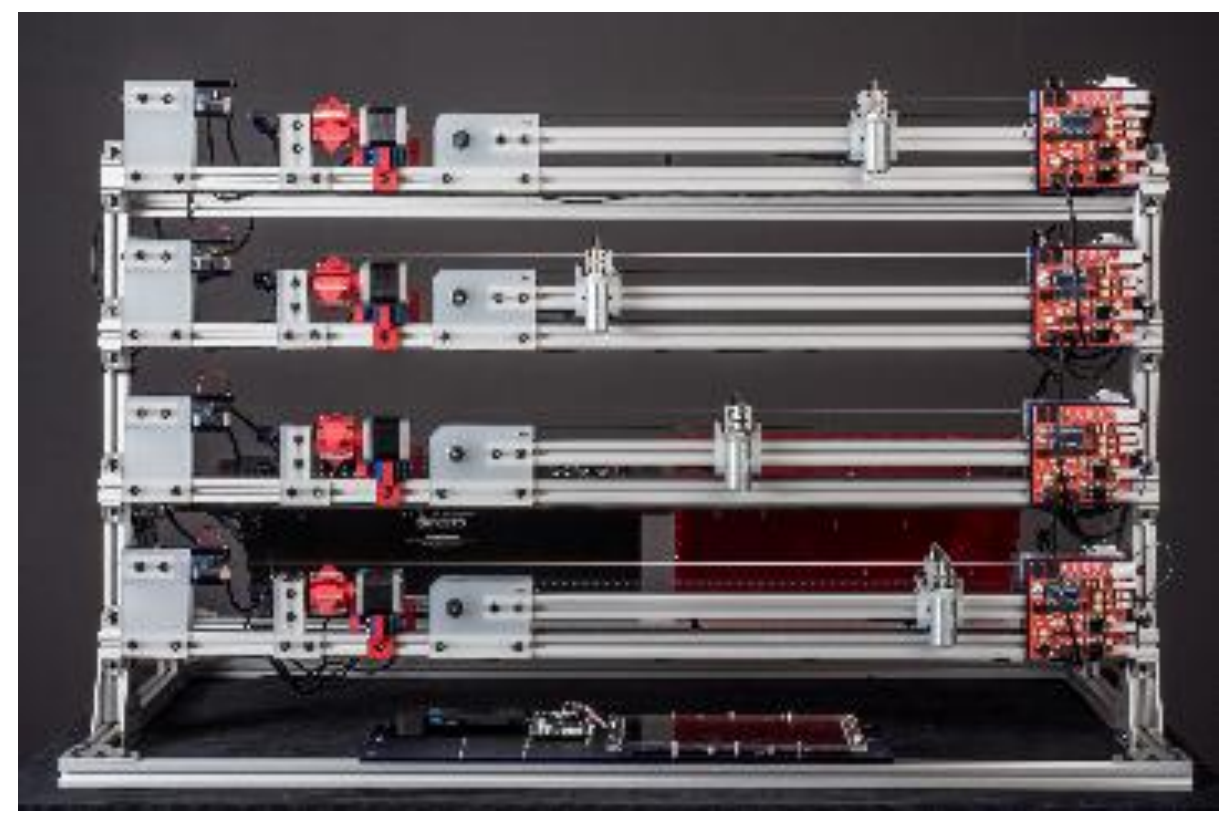

Fig. 1. MechBass - a four string robotic bass-guitar 


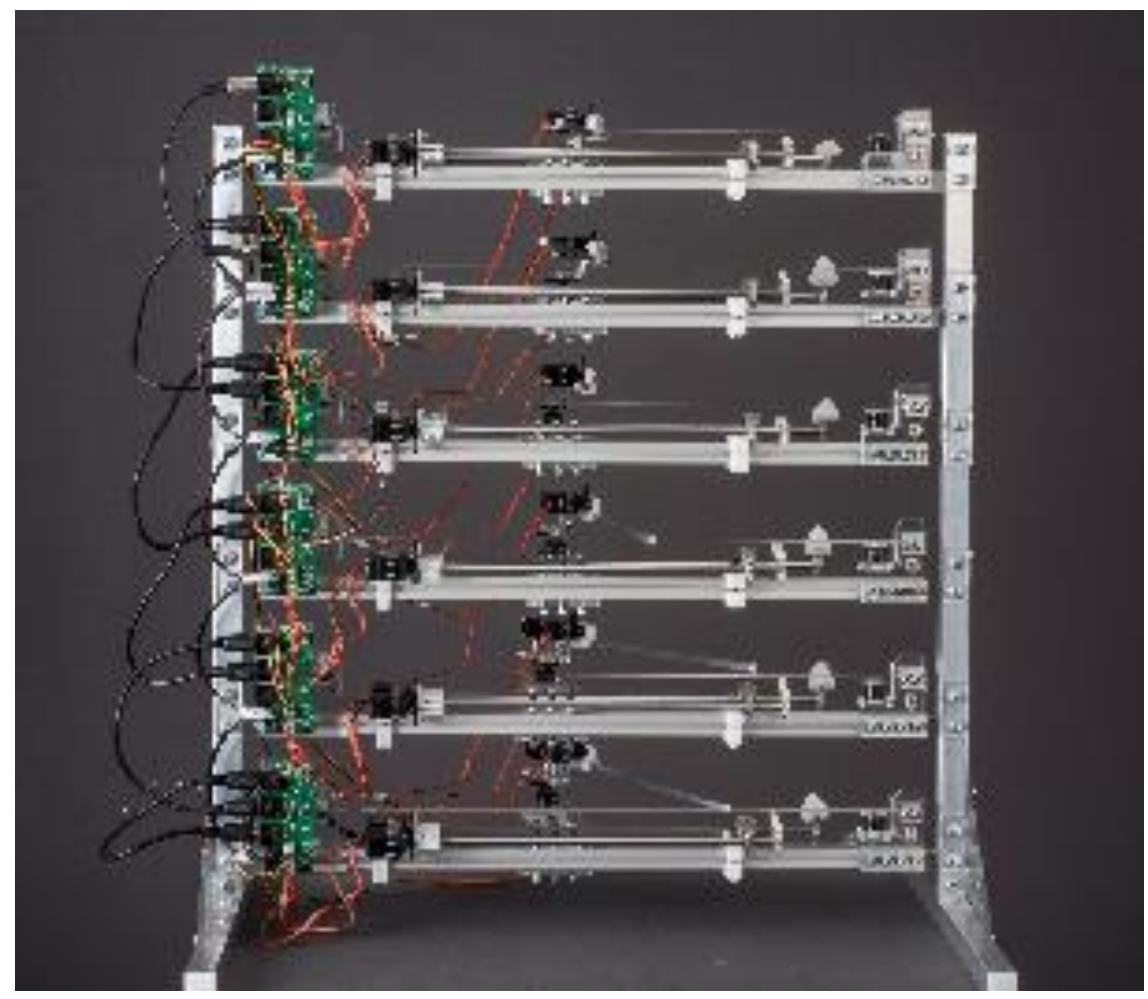

Fig. 2. Swivel2 - a six-stringed modular robotic guitar

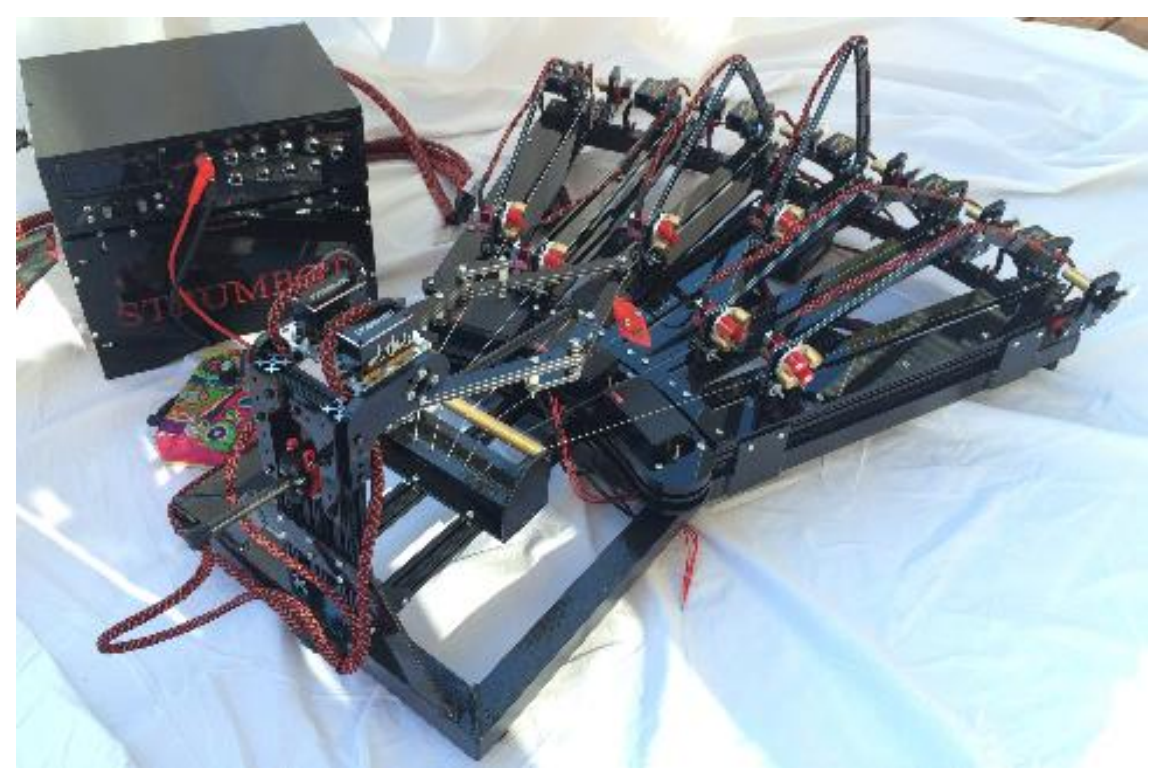

Fig. 3. StrumBot - an integrated six-string guitar [18] 


\section{$5 \quad$ Specific Learning Objectives}

A criticism often levelled at PBL-type courses is that the students "don't know what they don't know". In other words, they may have a complete ignorance of a particular technique or knowledge and require some direction in order to obtain such information or to develop the required skill. Poorly designed PBL courses can leave such issues entirely up to the students, meaning that they can miss what "traditional" courses would deem to be essential.

We seek to mitigate this by providing the students with an explicit list of core learning objectives in the course. This also ensures that the instructors are confident that each student is aware of these expectations and can appropriately guide them. For this course, our learning objectives (phrased as questions) are:

- How can we effectively conduct a literature review in order to help in the development of a new mechatronic assembly?

- What are important audio features in different contexts? What kind of feature extraction systems are appropriate in a mechatronics context? How can we create a feature extraction toolchain?

- What types of actuators may be used in mechatronics? What actuator criteria should be taken into consideration when developing and evaluating a mechatronic subsystem?

- What actuator parameters are important to consider in this context, and how do different requirements lead to different component choices?

- How can we integrate multiple mechatronic subsystems? How does the integration of multiple subsystems affect design decisions?

- How do we choose the most important design criteria when there are multiple possible development avenues? Further, how may this be assessed?

- How can we utilise a CAD/CAM workflow approach to aid a mechatronic project development? How can we benefit from an iterative design flow in improving a mechatronic system?

This list comprises both knowledge and skill set considerations. The next section outlines how we divide the course into two components - the first primarily formative, the feedback from which informs the second and more difficult summative component.

\section{Formative and Summative Assessment}

The course is designed to guide students working in groups, through the design issues of the construction of a major mechatronic musical device. For the first iteration of the course, we are choosing the chordophone as our device of preference. The reasons for this are both pragmatic and inspirational. MechBass inspires the students to equal or better its achievements. Pragmatically, the chordophone provides us with the opportunity to discuss a range of relevant mechatronic topics, including sensors, actuators, drivers, microcontrollers, data acquisition, $\mathrm{CAD} / \mathrm{CAM}$ techniques, rapid proto- 
typing techniques (3D printing and laser cutting) and workshop skills in the creation of the chassis. There is also significant flexibility in terms of the design of the chordophones elements - there is no one best technique. However, crucially it also allows a division of the course into two components, the first is a strongly formative learning exercise, and the second is a combination of formative and summative.

There are three critical components of a mechatronic chordophone, the strummer/picker, the string damping mechanism, and the pitch-shifter (which is also referred to as a fretting mechanism). The strummer (or picker) and the damper are mechatronically simpler than the pitch-shifter. There are a variety of techniques that we (and others) have employed to effect a strumming/picking device [21], including push-pull solenoids, stepper motors, servo motors, DC motors on a tilt to alter the attack strength on the string [15] and modified SCARA robot arms [18]. Similarly, damping mechanisms often employ solenoid actuators or DC motors to move some form of dampening material into contact with the string.

Our course therefore begins with the design of the strummer and damper. It is our desire to not only develop mechatronic skills in our students but also to reinforce and shape their thinking as senior engineering students. Therefore early in the course the students are required to prepare an individual literature review detailing previous work on strumming mechanisms, analysing and identifying strengths and/or shortcomings of these previous approaches and consequently motivating their own designs. This literature review is only worth $5 \%$ of the course grade, but will be used later in the capstone assessment. We expect a variety of skills to be exhibited depending upon students' past experience with formal report writing. Therefore, the low assessment weighting is a reflection on the formative nature of such a review at this stage - all submissions will be individually edited and critiqued to help improve student performance.

The students are then guided through the development of their nominated damping and strumming/picking mechanisms. A group report must be produced that discusses the related works, methodology, evaluation of the system, and conclusion. The working devices must be demonstrated and each member of the team must be involved in the presentation. Students must also produce an individual report that clearly identifies their contribution to the project, and every member of the group completes a peerassessment form whereby they can express their (confidential) opinions on the performance of the other group members. The result of these reports, peer-evaluations and demonstration is a grade that comprises $20 \%$ of their final course mark.

Part 2 of the course requires the design of the far more complex pitch-shifter/fretter mechanism. It was initially envisioned that the groups would be changed at this stage to provide some heterogeneous mixture of project contributors. However, this did not go as planned (as will be discussed later). Again, this project begins with the requirement for a formal literature review. This is a summative assessment - ample feedback was provided during Part I of the course, and is worth $10 \%$ of the final course grade.

The students are then guided in the PBL style, through the design and development of this pitch shifting device, and the integration of this with the previously designed strummer/picker. 
Of course we need to be aware that failure in Part I of the course should not preclude success in Part II, and therefore we have available some pre-built strumming devices should a group not have their own. This is a major project and it is too risky (in the authors' opinions) not to have an interim milestone. Therefore, at the half-way point of the project, a group mark of $5 \%$ is awarded for the preparation of a progress report. There is no attempt to identify individual contributors at this stage.

The final report, demonstration, and presentation follows the same format as for the strummer/picking mechanism and individual grades are awarded. This comprises $50 \%$ of the final grade.

The final $10 \%$ of the assessment is a group mark and requires the production of an appropriately formatted conference submission paper. This will be submitted to an appropriate forum, perhaps NIME (New Interfaces for Musical Expression) or other relevant conference. Although papers from all groups will be submitted, it will not be possible to know of paper acceptance in advance of awarding a grade for the paper. The authors' experience in submitting and reviewing such papers themselves must suffice.

\section{$7 \quad$ Managing Workload}

The primary author of this paper has developed, coordinated, and delivered a number of mechatronic papers, with varying levels of emphasis on skills and knowledge content. Problems have occurred in some of these courses specifically those that use "open-ended" assessment projects.

Such open-ended projects can often consume far more student time than was originally expected. Whilst one approach is to impose formal constraints on the expected student output, the authors feel that this unduly constrains the students' creativity, problem solving innovation, and the development of life-learning habits where they take control of the final quality of the project. Nevertheless, in our degree programme, students are expected to undertake four courses per trimester, and an on-going problem is students becoming so motivated and engrossed in their mechatronic projects that they do not put sufficient time into their other courses.

The authors strongly believe that such motivation is an excellent outcome, but if not handled carefully, this additional workload and the resulting lack of work-lifestyle balance leads to increasingly levels of stress, degraded well-being, and potentially poor performance in other required (but perhaps less motivating) courses. Our compromise for this course is to clearly define what our expectations are - detailing in writing to the students what a $\mathrm{C}$ (minimum pass grade) output would look like, what a $\mathrm{B}$ grade would require, and what must be achieved for the $\mathrm{A}$. This gives the students prior knowledge of the time implications and assists them to balance their overall workload.

\section{Planned Extension Work}

We are prepared for highly capable groups in terms of potential extensions to the project if necessary. The performance of mechatronic chordophones is directly related 
to the placement of the pitch-shifting mechanisms. If these can be intelligently placed so that the movement to the next incoming note is minimal, then the device can play at a far faster rate. Optimising this requires a level of artificial intelligence. The same note can be played on different strings with different positioning of the fretter. Prerecorded material can be pre-processed to determine such optimal positionings through a non-trivial algorithm. The students could potentially investigate several forms of artificial intelligence (AI) algorithms to help determine these. Testing and evaluation of such pre-recordings is mostly straight-forward.

Of course the students might be aware of this and design a system that has a series of solenoids in place that require no translational movement - an activation of the solenoid will clamp the string at that pre-determined position. We would not prevent the students selecting such an option, and this does completely mitigate the issues noted above, but the limitations of such strategies are well known in the music field (e.g. many non-Western musical systems will be excluded and a range of musical expressions such as sliding movements would not be possible).

An alternative to the software intensive AI algorithm development is the creation of an electronic effects box that emulates the range of sounds available to professional guitar players. There are several effects that could be implemented depending upon the student skill and time available.

\section{$9 \quad$ Formative Results}

The course ran for the first time from July through to October 2016. The first surprise for us was that enrolments in the course doubled after the first week, when word was spread about how the course was being run, and what the final objective was to be. This was extremely pleasing and we ended up with 13 students whom we divided into three groups of 5,4 , and 4 students.

The initial formative component of the course resulted in a diversity of ideas that we could not have predicted. These are illustrated in the figures below and are indicative of the success of the PBL approach. The students were all given a set of objectives, which they divided into "hard" constraints - those objectives that had to be achieved, and "soft" constraints that could be compromised in the over-arching design (i.e. features that are desirable but not essential).

The hard constraints were:

- Picking rate of at least 120 beats per minute

- Dampen string vibrations within $250 \mathrm{~ms}$

- Shift pitch over an octave with better than 25 cent precision $(100$ cents $=1$ semitone)

- Play all 12 notes in a chromatic octave within 6 seconds (A2 to G\#3)

- Control the device via MIDI commands

Examples of soft constraints include the ability to play effects such as vibrato and slide, as well as inducing a closer "human-feel" attribute to the sonic output (as opposed to the machine-made sound). Faster and more accurate responses were also desirable if these could be achieved. 
To illustrate, Group I became concerned with the material of the string actuator (plectrum) and damper. Following an extensive literature reviews, the group decided to focus on the issue of the machine-made nature of the sound in the majority of mechatronic chordophones. Therefore, they set their main soft constraint as a desire to mimic the natural compliance of human flesh, both during the plucking, and when finger or palm muting. Consequently, they designed two forms of plectra - one using a standard guitar pick, the other using a "flesh-like" silicone "finger". These can be seen in the foreground of Fig. 4 where a stepper motor selects between the different forms of actuation (detached from the chordophone for the purposes of the photograph). It is more difficult to resolve the damping mechanism just to the left of the silver rectangle that is the magnetic string pick-up.

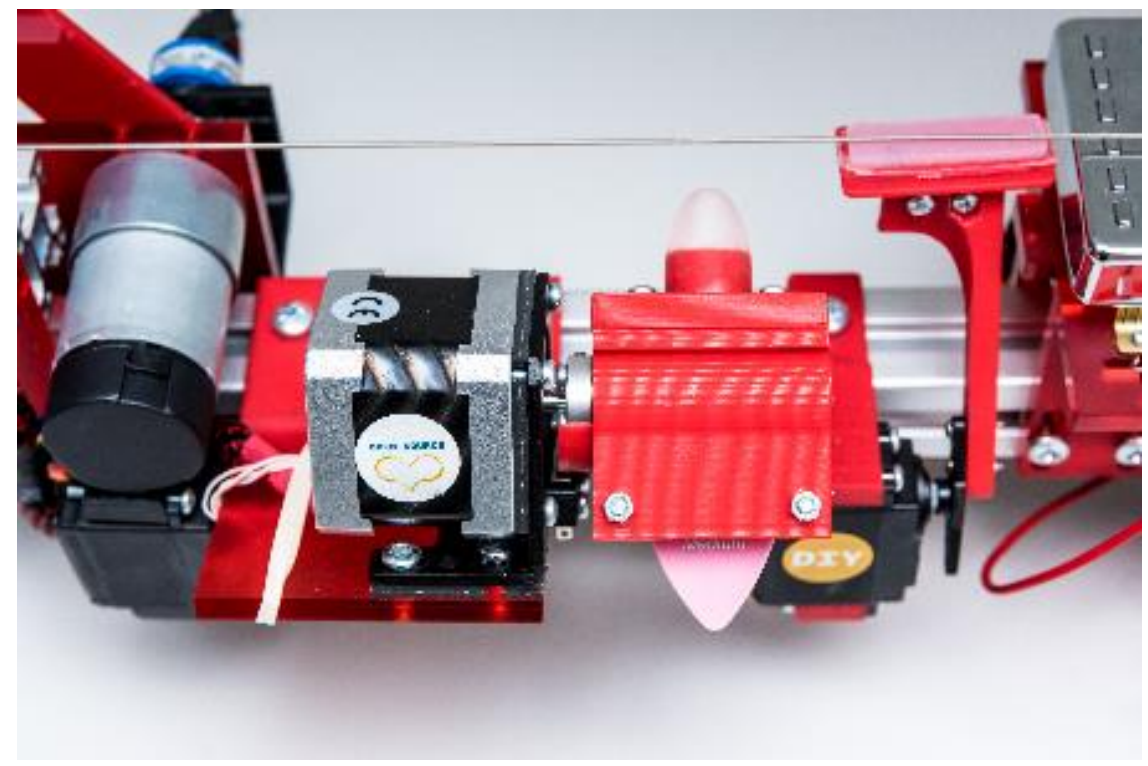

Fig. 4. Group I picker and damper. Note the silicone material.

Fig. 5 illustrates Group II's approach. They have opted for a higher speed plucking mechanism by installing five picks on a 3-D printed holder attached to a stepper motor. Additionally, an evaluation of pre-existing mechanisms (particularly MechBass and Swivel II), Group II identified the stiff mechanics of plucking in these previous systems - which results in an undesirably loud "pick slap" - as a problem they wished to improve upon. Hence, their plucking mechanism is held in place by the springbased structure in the foreground, designed to add compliance to the picking mechanism. These students elected to dampen the string's vibrations by a "scissor-type" clamping that can be seen on the far left of Fig. 5 .

Fig. 5 also illustrates the electronics that are provided to the students (right of the figure). This facilitates a MIDI command to control the actuators (pitch-shifters, strummer, damper), and receive input from sensors such as the magnetic pick-up and pitch-shifter position. 


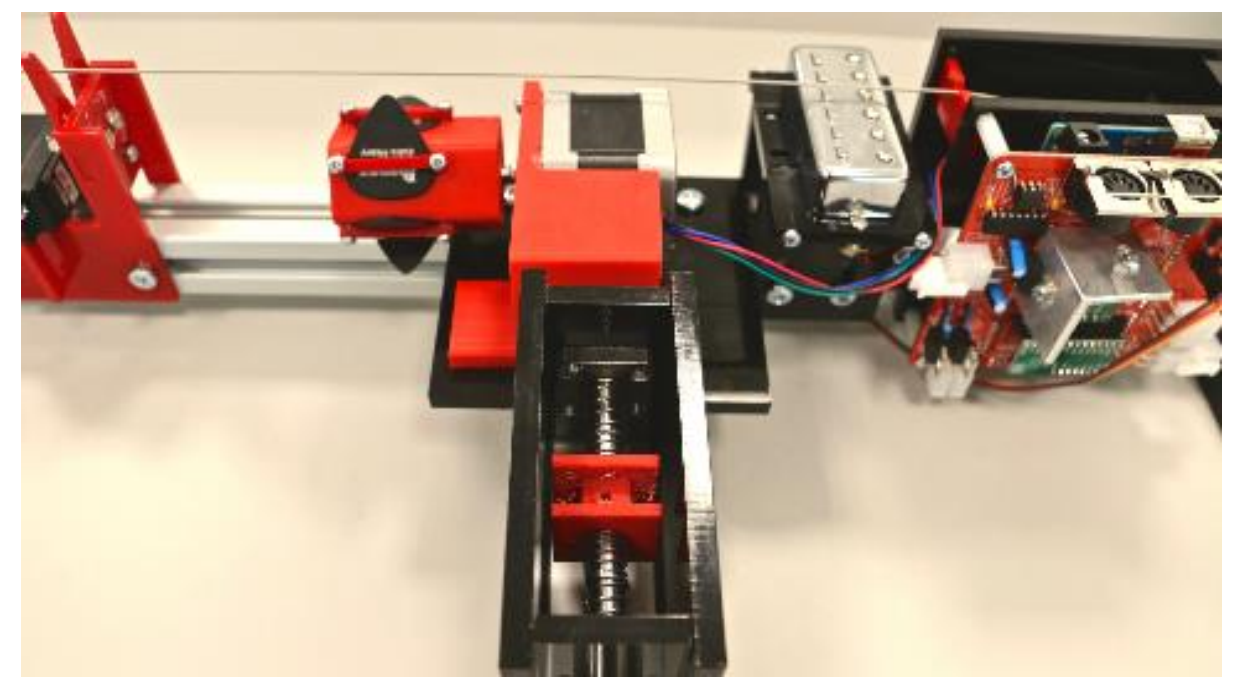

Fig. 5. Group 2: Note the compliant actuation for the picking mechanism.

Group III emphasised the speed of picking with eight picks on a rotary actuator. They also noted that a human player will vary the strength of the pluck - harder for a louder, sharper note, softer for a gentler striking. To implement this, they attached the picking mechanism to a servo-operated cam (illustrated in the lower right of Fig. 6) that pushes the rotary picker closer or further away from the string.

This group also devised a different damping mechanism, viewable on the left of Fig. 7. Upon a damping command being issued, a servo rotates these felt pads into making contact with the string.

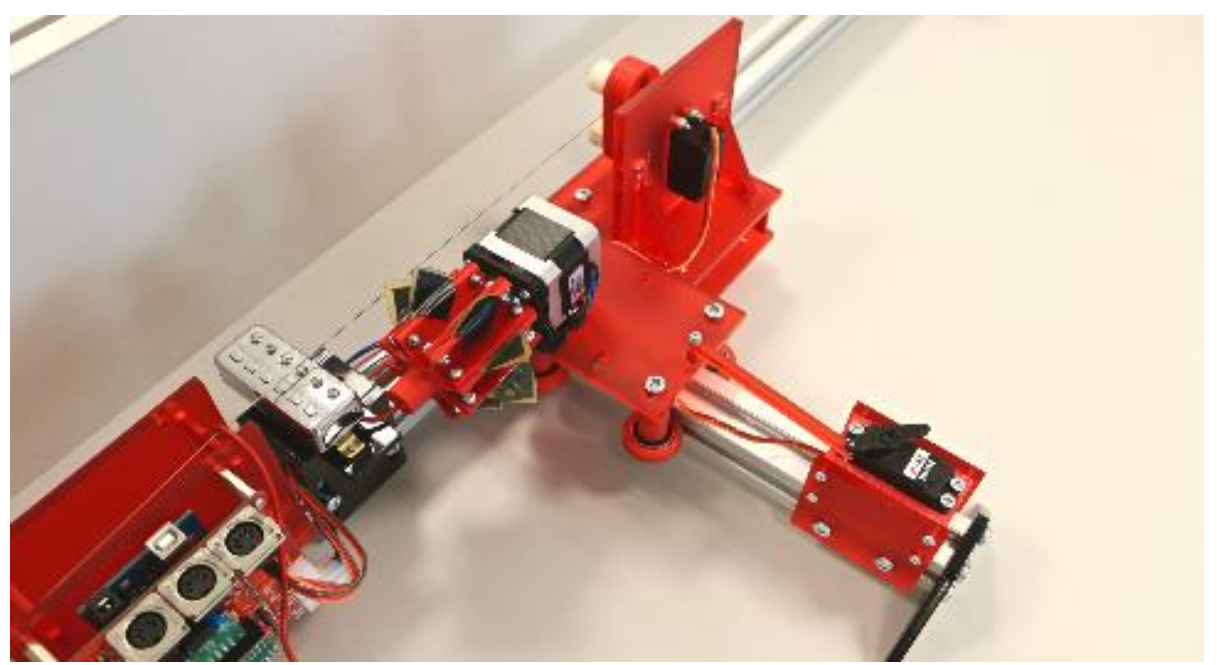

Fig. 6. Group III: Note here the servo driving a cam to advance or retard the picking mechanism. 


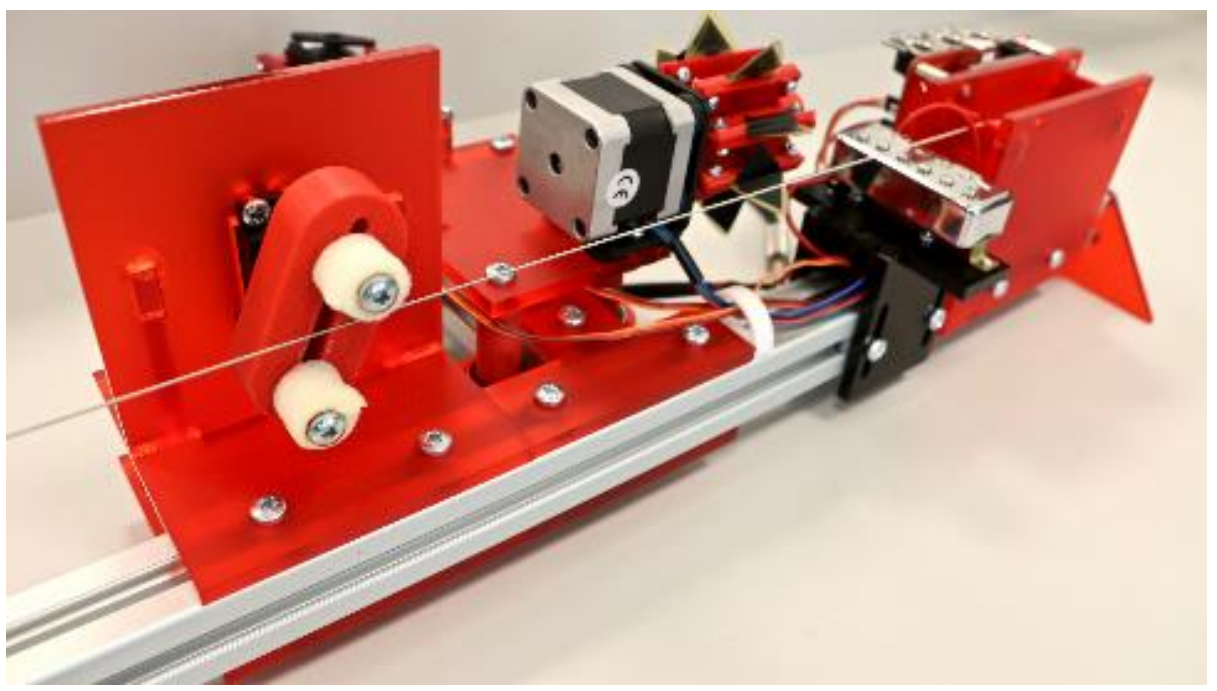

Fig. 7. Group III also produced a different form of damping actuation.

One immediate impact of the diversity of designs at this stage was that the students fought very hard to stay in their original groups, rather than change as we had planned. They felt ownership of their designs, were proud of them, and wanted to see the entire chordophone completed with the same group. After several delegations visited the course coordinator, we acquiesced.

All of the designs worked - all with their own nuances and differing timbre. As discussed previously, we were mindful of the oft-failure of PBL courses to not award the higher grades - there can be a tendency to reserve these for the "prefect project", so the expectations of $\mathrm{A}, \mathrm{B}$, and $\mathrm{C}$ grades were enforced. The top grade awarded for this performative was $96.2 \%$ (an $\mathrm{A}+$ ) for a student who normally scores $15 \%$ lower. The lowest grade at this stage was a 76\% $(\mathrm{B}+)$ - noting that the lowest passing grade possible in most New Zealand universities is $50 \%(\mathrm{C}-)$.

\section{Summative Results}

For the latter part of the course, the students were expected to apply their learning, and engage in self-directed learning (core to PBL pedagogy). The students were now tasked with designing the more complex pitch-shifting mechanism, which had to be integrated with the previously designed damping/picking system. Less specific direction was provided in the laboratories and a self-directed literature review was now required. Software had to be written by all groups to control and coordinate their systems, and the entire working device had to be demonstrated during a grading presentation. Quantitative and qualitative testing was also required to demonstrate that the design met the project specifications. All devices were required to play a full chromatic octave in under 6 seconds with the pitch being within 25 cents (a cent is $1 / 100^{\text {th }}$ of a semitone) of target. The ability to produce vibrato, slide guitar, and har- 
monic ringing were desired, but not required. Nevertheless, as previously mentioned, the students were made aware of the design desire for the robot to be able to exhibit music expressivity.

Informed by their varying interpretations of their literature reviews, the three groups took a variety of different approaches. Group I was inspired by StrumBot [18] and developed a fretter system using an RC servo mounted to a linear motion carriage. The carriage is moved by a SCARA arm driven by a DC gear motor (Fig. 8). As can be seen in Fig. 9, the carriage uses four wheels with inset bearings to run in the slots on the aluminium extrusion. The SCARA arms are laser cut by the students out of $3 \mathrm{~mm}$ red Perspex, and the lengths are chosen to minimise motor torque while travelling more than half the string length. Although there was some backlash from the gear box, they achieved an output resolution of 0.11 degrees.

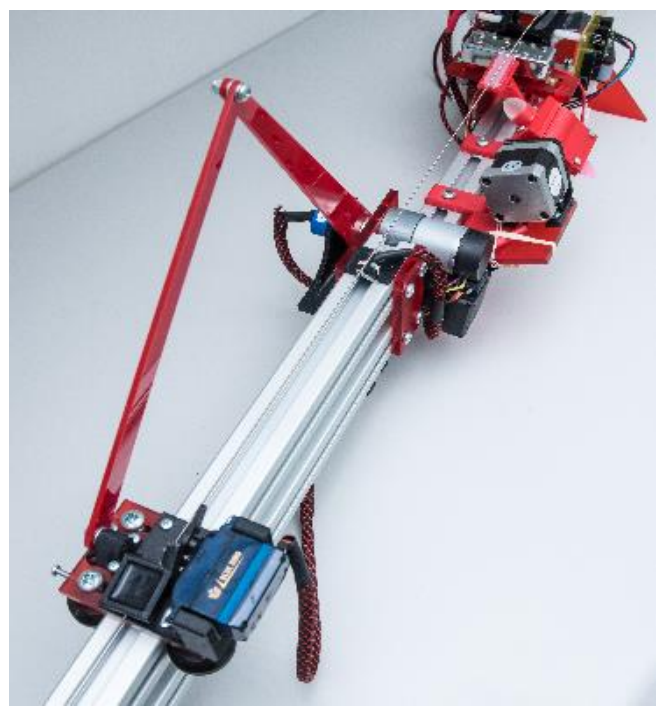

Fig. 8. Group I's SCARA arm pitch-shifting system

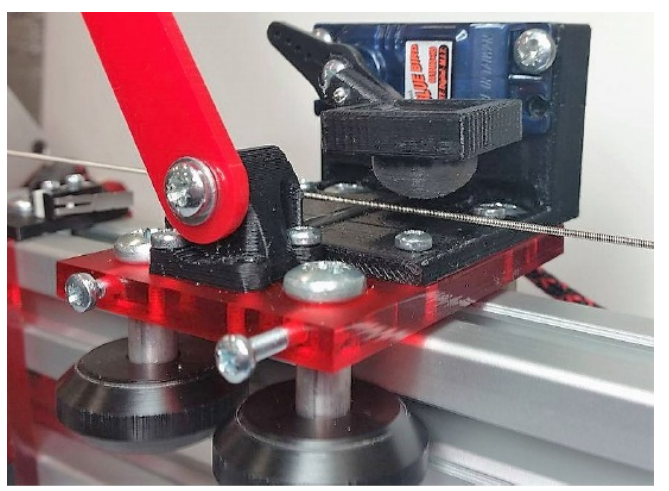

Fig. 9. Group I's string clamping system (note the compliant material.) 
Group II decided to implement a slide guitar effect, which meant that the string clamping mechanism must be movable. They therefore incorporated a wheeled platform powered by a stepper motor, timing pulley, and timing belt. They machined wheels to fit within the Slot-pro inserts (Fig. 10), and for aesthetics, mounted the timing belt in the inset side of the Slot-pro rail (Fig. 11). This means that only a single length of timing belt is required rather than a loop, enabling easier tensioning and more compactness. The use of a stepper motor of course means that a feedback system is not crucial.

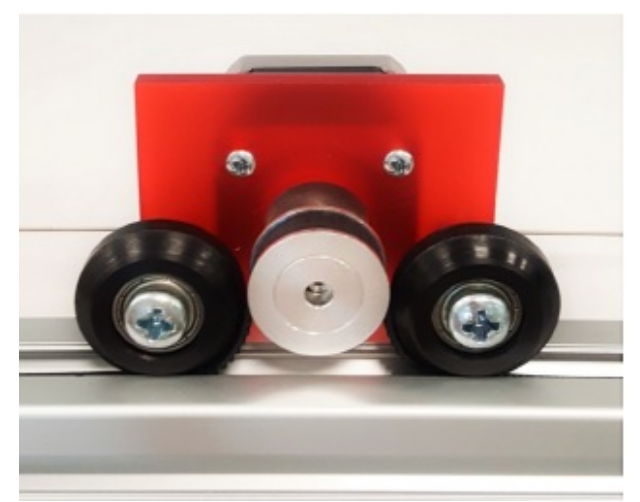

Fig. 10. Group II 's trolley system

They chose a servo as the fretter actuator, as illustrated in Fig. 11. This allows the force applied to the string to be altered by changing the angle of the servo arm. This tightening or loosening of the string allows vibrato to be achieved. The contact point of the fretter is a freely rotating aluminium machined rod which allows a slide guitar effect without an accompanying scratching sound. A second padded rod makes contact with the non-plucked portion of the string, preventing unwanted excitations.

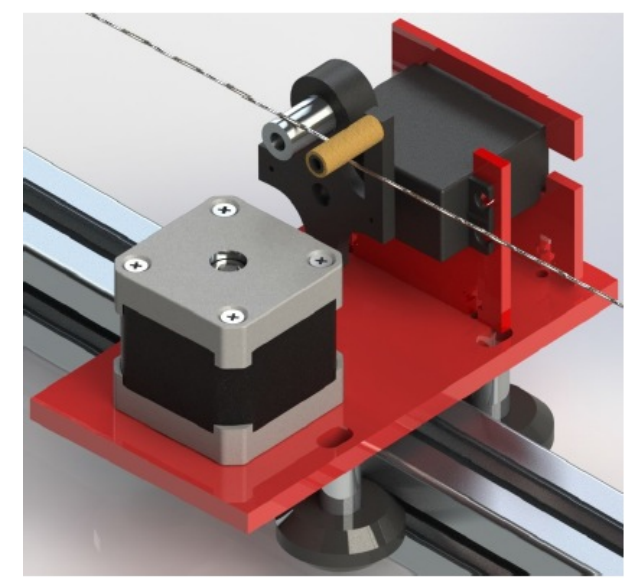

Fig. 11. Group II's string clamping and vibration minimising system 


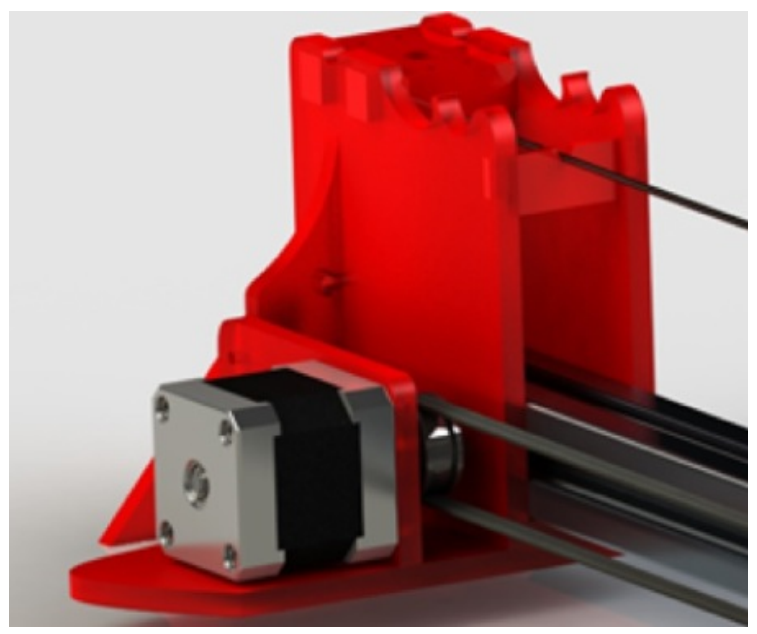

Fig. 12. Group III's looped belt pitch-shifting system

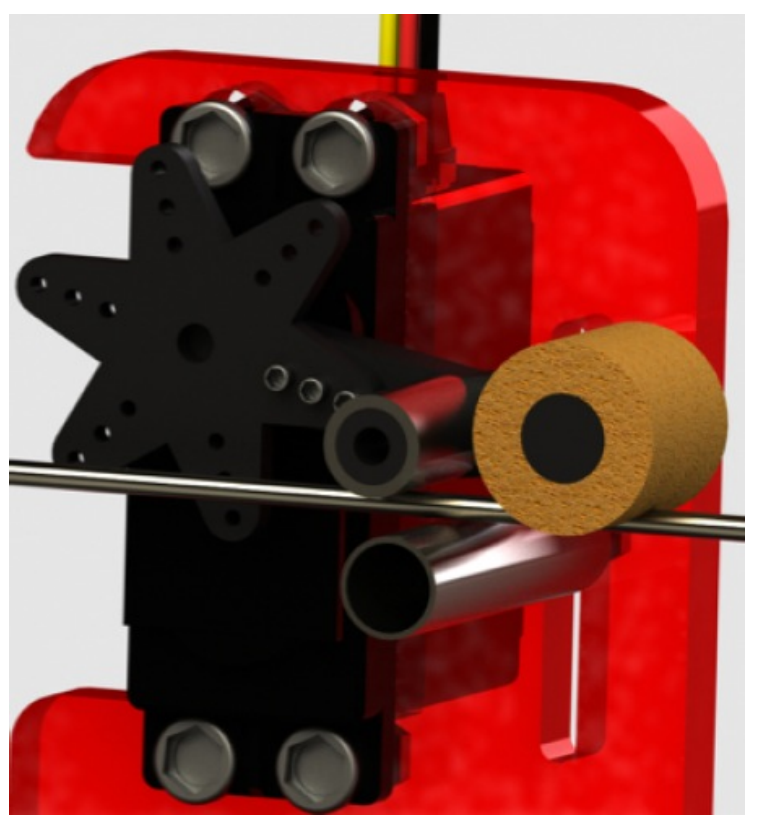

Fig. 13. Group III's clamping and vibration minimising system

Group III also implemented a sliding actuation carriage, but took the perhaps easier route of using a timing loop in a manner similar to MechBass (Fig. 12). The fretting clamp is similar but has a fixed lug that pinches the string when the servo lug rotates against it. This design also has a damping pad on the non-plucked side of the string (Fig. 13). Fig. 14 illustrates the three completed chordophones. 

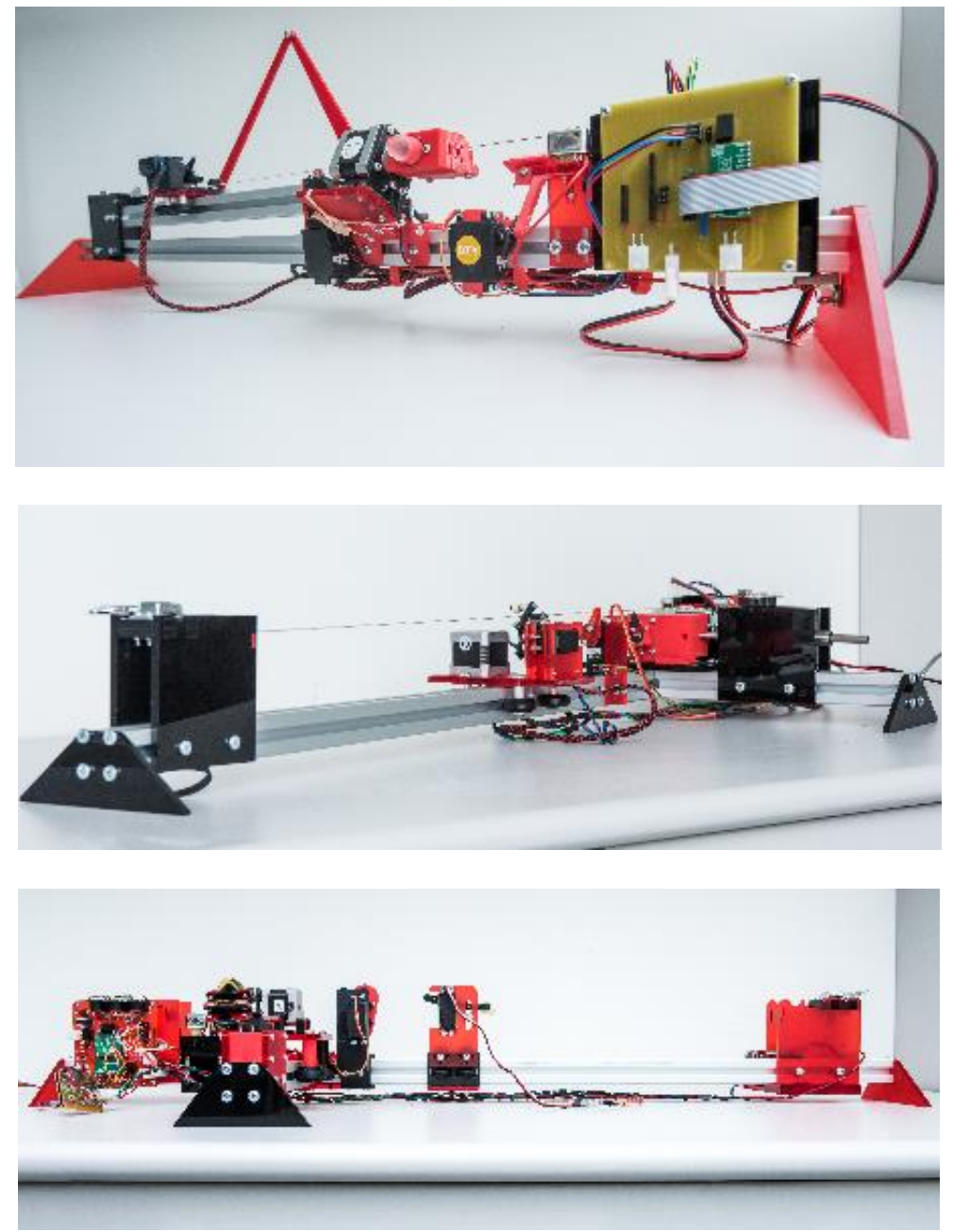

Fig. 14. Final designs, groups I, II, and III (top to bottom)

\section{Quantitative Results}

The students were required to quantitatively demonstrate that their designs met the required specifications, although no direction was given as to how they should display/present these quantitative results.

Some objectives were rather easy to demonstrate however, and all groups produced a plot similar to Fig. 15 below to demonstrate that they could achieve the 12 notes within 6 seconds requirement. Group I has a fastest run over these notes of 4.1 seconds. Group II played the required 12 notes in 4.9 s. Group III achieved 13 notes (Fig. 15) in the required 6 seconds. 


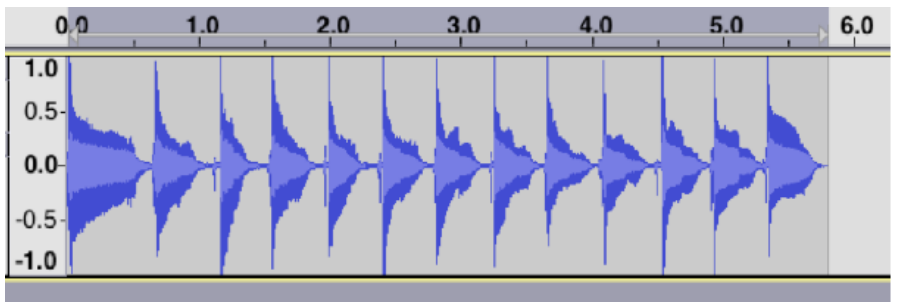

Fig. 15. Group III's timing for 13 note actuation

Different picking rates were of course achieved. Expectedly, Group III's 8 pick rotary system was the fastest at 960 picks per minute, vastly in excess of what the fastest human can achieve. Group II achieved 160 picks per minute, and Group I, 320 picks per minute.

The precision of the notes was demonstrated in a variety of ways. For example, Fig. 16 from Group II shows the average deviation (in cents) of notes at semitone intervals averaged over 10 readings. The average deviation in tone accuracy is a very respectable 2 cents, with the largest average error being only 5 cents. The large variation as evidenced by the error bars is not explained (and this did cost them marks).

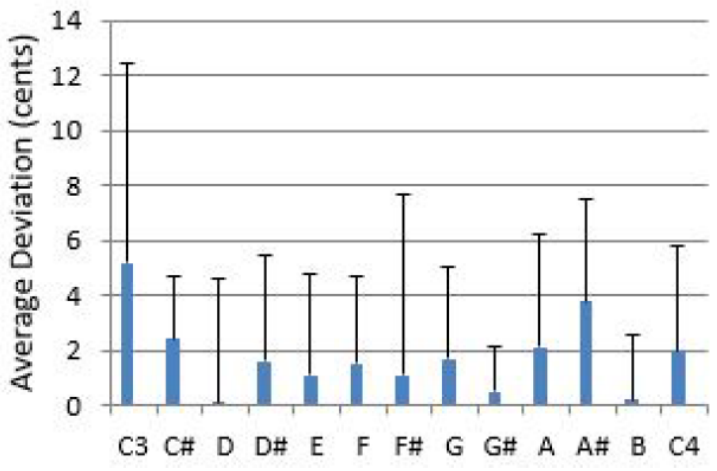

Fig. 16. Group II's note accuracy

Whilst all groups claimed to have met the accuracy criteria, some had to argue that they met it "on average" whilst others met it for every note.

In addition to the performance, where various effects were demonstrated, figures were produced that show the resultant spectrograms of harmonic ringing (Fig. 17, note the prominent first and second harmonics), slide from C3 to E3 (bars have been added in Fig. 18 to more clearly indicate the change in frequency/pitch of the note), and vibrato (Fig. 19 noting the latent oscillations in the higher harmonics above the target note - observable as the patch of high energy shown in yellow). Fig. 20 was included by Group III to illustrate the success of their slide technique.

Finally, the students also produced a variety of plots to demonstrate features such as "Attack Time" (Fig. 21), damping response, "Brightness" (Fig. 22) and changes in RMS energy to further explain their device's capability. 


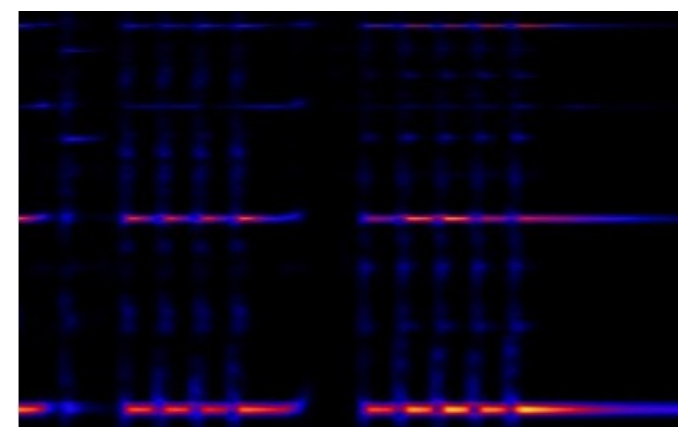

Fig. 17. Group II's spectrogram of the harmonic ringing produced when notes E4 and E5 when E3 are played

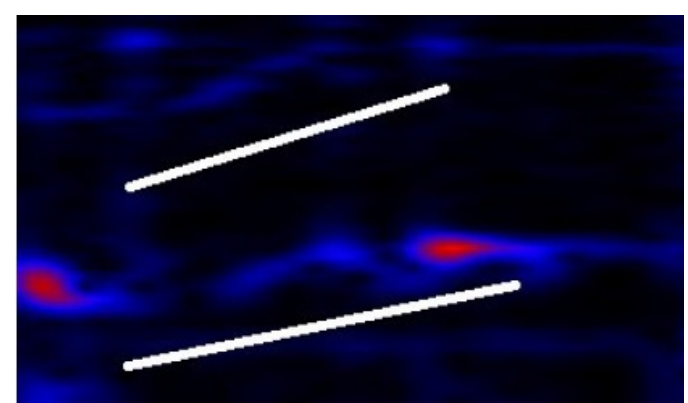

Fig. 18. Group II's spectrogram of the fretter slide effect from C3 to E3 (through an amplifier).

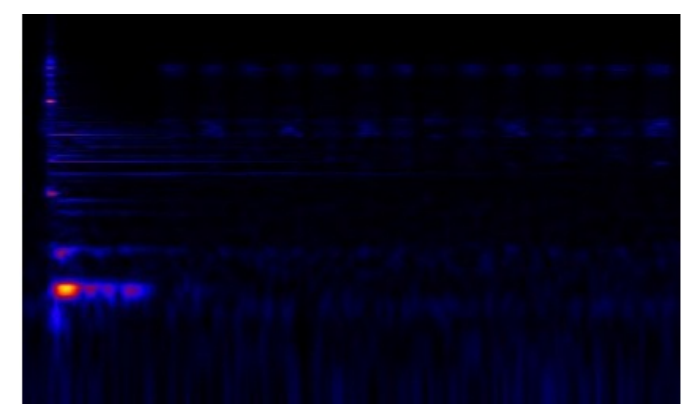

Fig. 19. Group II's spectrogram of an amplified E3 note sustained with vibrato

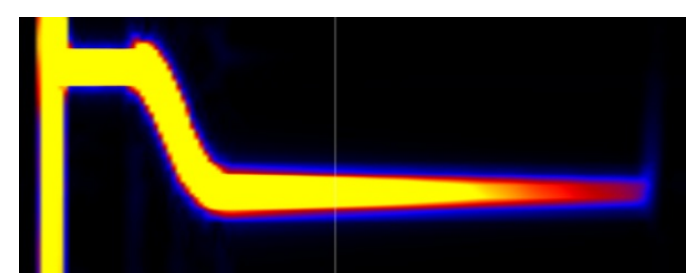

Fig. 20. Group III's spectrogram showing a legato slide between C and G. Yellow shows the peak of frequency. 


\section{Student Results}

Of the $61 \%$ of students who replied to the satisfaction survey, on a five point Likert scale, $62.5 \%$ of the students gave the course the highest grade for enjoyment. The remaining $37.5 \%$ scored it only one point lower. They rated the practical learning and PBL approach as being particularly enjoyable with the instant feedback and strong relationship between practice and theory. $75 \%$ of the students rated the quality of course as excellent (the highest grade on the Likert scale). We were concerned that the course might have too high a workload, however, all but one student rated the course as having an equivalent workload to similar level courses.

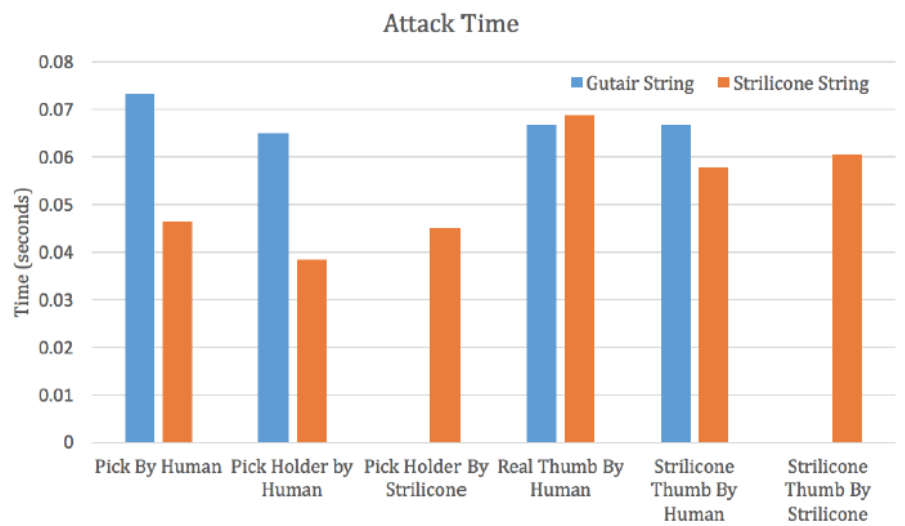

Fig. 21. Group I illustrating the attack time on both a standard guitar string and their chordophone string using a regular pick, a pick in the holder, real thumb and silicone thumb.

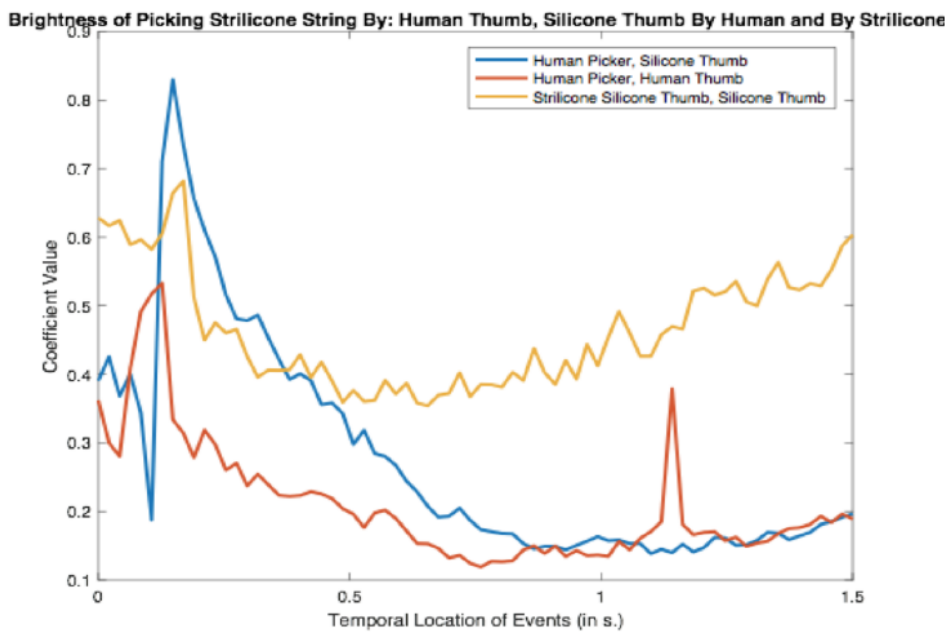

Fig. 22. Envelope of Group I's response to a silicone thumb, real thumb, plucking a guitar string, and the chordophone string. 
The final grades were extremely pleasing, with three students gaining the highest award of $\mathrm{A}+$, six gaining the award of an $\mathrm{A}$, one $\mathrm{B}+$, one $\mathrm{B}$, and one (who had medical issues) achieving the marginally passing score of $\mathrm{C}$-. In hindsight, and for future iterations of the course, we do need to add more discriminating assessment - some of our A grades could perhaps have been A- or B+ had we effected this. However, overall, we do feel that the grades reflected the engagement of the students and the quality of work they produced.

\section{Conclusion}

We consider this course to be a significant success, although we still have to run it with a full international cohort. The students produced research quality mechatronic chordophones and high quality conference submission papers (these have not been submitted at the date of writing). Student satisfaction and engagement with the course was exceptional and almost all expressed specific appreciation of the PBL pedagogy.

They leave this course with an increased knowledge of mechatronic systems, including motor actuation, real-time sensing, software control, 3D printing, laser cutting and mechatronic assembly. The course design allowed them to combine their learning with an expression of creativity, and the diversity of final designs fully exemplifies this - there was no direct copying from existing (or peer) designs. Each group took a different focus and produced a device that sounds unique.

We are excited about the future projects we will pursue in later iterations of this course.

\section{References}

[1] D.A. Carnegie, P. Andreae, C.A. Watterson and K. Bubendorfer, "The Development of Postgraduate ICT Programmes - for an Industry that does not want them", in Proc. 2016 IEEE Global Engineering Conference, pp 702 - 708, April, 2016. https://doi.org/10.1109/EDUCON.2016.7474627

[2] J.E. Mills and D.F. Treagust. "Engineering education-Is problem-based or project-based learning the answer?" Australasian Journal of Engineering Education 3, Jan 2003, pp 2-16.

[3] H.A. Hadim \& S.K. Esche, "Enhancing the engineering curriculum through project-based learning". In Frontiers in Education, 2002, 32nd Annual (Vol. 2, pp. F3F-1). https://doi.org/10.1109/fie.2002.1158200

[4] M. Frank, I. Lavy \& D. Elata, "Implementing the project-based learning approach in an academic engineering course". International Journal of Technology and Design Education, 13(3), 2003, pp 273-288. https://doi.org/10.1023/A:1026192113732

[5] R.A. Stewart, :Investigating the link between self-directed learning readiness and projectbased learning outcomes: the case of international Masters students in an engineering management course". European Journal of Engineering Education, 32(4), 2007, pp 453 465. https://doi.org/10.1080/03043790701337197

[6] L. Springer, M.E. Stanne \& S.S. Donovan, "Effects of small-group learning on undergraduates in science, mathematics, engineering, and technology: A meta-analysis". 
Review of educational research, 69(1), 1999, pp 21 - 51. https://doi.org/10.3102/ 00346543069001021

[7] Y.V., Zastavker, M. Ong, \& L. Page, "Women in engineering: Exploring the effects of project-based learning in a first-year undergraduate engineering program". In Frontiers in Education Conference, 36th Annual, October 2006, pp $1-6$.

[8] [Knight, D. W., Carlson, L. E., \& Sullivan, J. F. (2003). Staying in engineering: Impact of a hands-on, team-based, first-year projects course on student retention. age, $8,1$.

[9] C.L. Colbeck, S.E. Campbell \& S.A. Bjorklund, S. A. "Grouping in the dark: What college students learn from group projects". Journal of higher education, 2000, pp $60-83$. https://doi.org/10.2307/2649282

[10] D.A. Carnegie, A. Kapur, G. Gouws, G. and C.A. Watterson, "Student Retention in a Mechatronics Programme: Motivating Engineers to Learn Through Music and Creativity." Proceedings of the $15^{\text {th }}$ International Workshop on Research and Education in Mechatronics, September 2014.

[11] Misra, Ananya, Douglas Blank, and Deepak Kumar. "A music context for teaching introductory computing." ACM SIGCSE Bulletin. Vol. 41. No. 3. ACM, 2009. https://doi.org/10.1145/1562877.1562955

[12] G. Wang and P. R. Cook, "ChucK: A Concurrent, On-the-fly Audio Programming Language," in Proc. of the Int. Computer Music Conf., 2003.

[13] A. Kapur and M. Darling, "A Pedagogical Paradigm for Musical Robotics," in Proc. of the Int. Conf. on New Interfaces for Musical Expression (NIME). 2010.

[14] V. Shilpiekandula and Y.S. Song, "A Music-Based Mechatronic System for Teaching Modeling and Control." Proceedings of the ASME 2008 International Mecanical Engineering Congress and Exposition, paper number IMECE2008-66817 pp 203-209, November 2008. https://doi.org/10.1115/imece2008-66817

[15] J. McVay, D.A. Carnegie and J. Murphy, "An Overview of MechBass: A Four String Robotic Bass Guitar", In Proceedings of the $6^{\text {th }}$ International Conference on Automation, Robotics and Applications (ICARA), February, 2015, pp 179 - 184. https://doi.org/10.1109/icara.2015.7081144

[16] J. McVay, "MechBass - Hysteria”. Available https://www.youtube.com/watch ?v=5UYMnzXQEtw

[17] J. Murphy, D.A. Carnegie and A. Kapur, "Expressive Robotic Guitars: Developments in Musical Robotics for Chordophones," in Computer Music Journal, vol 39, no. 1, pp. 5973, Mar. 2015. https://doi.org/10.1162/COMJ a 00285

[18] R. Vindriis and D.A. Carnegie, "Strum-Bot - An overview of a strumming guitar robot", Proceedings of the International Conference on New Interfaces for Musical Expression Conference, Brisbane, pp 146-151, July 2016.

[19] J. Murphy, D.A. Carnegie and A. Kapur, "Little Drummer Bot: Building, Testing, and Interfacing With a New Expressive Drum System," in Proc. of the 2014 Int. Computer Music Conference. Athens, 2014.

[20] J. He, A. Kapur and D. A. Carnegie, "Developing a Physical Gesture Acquisition System for Guqin Performance," in Proc. of the 2015 Int. Conf. on New Interfaces for Musical Expression. Louisiana, United States, 2015.

[21] J. Long, "The Robotic Taishogoto: A New Plug'n'Play Desktop Performance Instrument," in Proc. of the Int. Cons. on New Interfaces for Musical Expression. London, 2014. 


\section{Authors}

Dale A. Carnegie has a BSc in Theoretical Physics and Applied Mathematics, an MSc with first class honours in Applied Physics and Electronics and a PhD in Computer Science. He is currently the Professor of Electronic and Computer Systems Engineering at Victoria University of Wellington where he is also the Dean of Faculty of Engineering. He heads Victoria University's Mechatronics Group, which specializes in Autonomous Mobile Robotics.

Mo H. Zareei is a sound artist and a music technology researcher. His experiments with sound covers a wide range from electroacoustic and electronic compositions to mechatronic sound-sculptures and installations. He holds a BSc in Physics from Shahid Beheshti University of Tehran, a MFA in Music Technology from California Institute of the Arts. He recently completed his PhD at Victoria University of Wellington where he is a lecturer in Sonic Arts and Engineering.

Jim Murphy is a sonic artist and engineering educator whose work focuses on mechatronic musical instrument design. He holds an undergraduate degree from California Institute of the Arts and a PhD from Victoria University of Wellington. His current area of study is focused on the development of parametrically-rich mechatronic chordophones and the means by which users may interface with them.

Craig Watterson is the Pastoral Care and Outreach Manager at the School of Engineering and Computer Science Victoria University of Wellington, New Zealand. In this role he is tasked with improving retention and recruitment of students in the $\mathrm{BE}$ (Hons) degree. His research field is engineering education with a particular focus on qualitative methods and approaches.

This article is an extended and modified version of a paper presented at the International Conference on Interactive Collaborative Learning (ICL2016), held September 2016, in Belfast, UK. Article submitted 10 January 2017. Published as resubmitted by the authors 13 February 2017. 